\title{
Statins in the Last Six Months of Life: A Recognizable, Life-Limiting Condition Does Not Decrease their Use
}

\author{
MARIA J. SILVEIRA, M.D., M.A., M.P.H., ${ }^{1,2}$ ANAMARIA SEGNINI KAZANIS, M.A., M.A., ${ }^{1}$ \\ and MATTHEW P. SHEVRIN, B.A. ${ }^{1}$
}

\begin{abstract}
Background: Some have advocated discontinuing statins in patients with life-limiting conditions. However, the extent of statin use at the end of life has yet to be described and whether statin prescribing may already be influenced by the presence of a recognizable, life-limiting condition is unknown.

Objective: To measure the prevalence of statin use during the last 6 months of life and determine if statin prescribing varies according to the presence of a recognizable, life-limiting condition.

Design: Matched, case-control trial nested within a retrospective, cohort study.

Setting/subjects: From 3031 VISN 11 patients who died in FY2004, we identified 1584 (52\%) receiving statins at least 6 months before death. Of those, we identified 337 cases with a recognizable, life-limiting condition and 1247 controls matched on number of comorbidities, age, and socioeconomic status.

Analyses: We used survival analysis to test the relationship between days without statins and the presence of a life limiting condition, while controlling for pills supplied and comorbidity score.

Results: There was no significant difference in the time off statins between cases and controls even though the study was sufficiently powered to detect one.

Conclusions: These findings underscore a missed opportunity to reduce the therapeutic burden upon dying patients and limit health care spending.
\end{abstract}

\section{INTRODUCTION}

$\mathbf{S}$ Tatins, or HMG co-A reductase inhibitors, are a family of medications used for the prevention of atherosclerotic disease. Multiple studies support their long-term use for the primary prevention of nonfatal myocardial infarction in people with cardiovascular risk factors (specifically peripheral artery disease, ${ }^{1-3}$ diabetes, ${ }^{1,4-8}$ and hyperlipidemia $\left.{ }^{3,9-14}\right)$. In addition, statins reduce the likelihood of recurrent myocardial infarction in patients with known coronary artery disease. ${ }^{3,7,8}$ Statins also reduce the rate of stroke in pa- tients with known cerebrovascular disease. ${ }^{15}$ For patients who live the 3-6 years it takes for risk reduction to occur, ${ }^{15-17}$ the benefits of statin therapy clearly outweigh the cost and side effects. For individuals suffering from life-limiting conditions, however, the benefit is likely to be less, and less certain, and the burden may be greater. Although such patients are typically excluded from clinical trials, we know that patients with life-limiting conditions do carry a greater risk of side effects from statin use; myopathy is more likely when patients are older, female, or have low albumins, hypothyroidism, electrolyte disturbances, in-

\footnotetext{
${ }^{1}$ Veterans Health Administration, Health Services Research and Development Center of Excellence, Ann Arbor, Michigan.

${ }^{2}$ Division of General Medicine, University of Michigan, Ann Arbor, Michigan.
} 
fection, hypoxia, renal insufficiency, hepatic insufficiency, or polypharmacy ${ }^{18-20}$ _conditions frequently present in patients with life-limiting conditions.

Given that the potential burdens of statin therapy for patients nearing the end of life may be great while the benefits are unproven and suspected to be small, Vollrath et al. ${ }^{21}$ in the Journal of Palliative Medicine proposed discontinuing statins for patients with lifelimiting conditions. Continuing statins in such patients, they argued, exposes them to risks not worth taking. Additionally, it burdens the health care system with unnecessary costs.

How often and how long patients with recognizable, life-limiting conditions are prescribed statins remains unknown. If the prevalence is low and the time on statins is short, it would suggest that physicians and patients already recognize diseases for which the usefulness of statins is limited. If the prevalence is high and the time on statins is long, however, such findings highlight an opportunity for better, quality care at less cost. For these reasons, we chose to examine the extent and timing of statin use, comparing individuals with recognizable, life limiting conditions to similar individuals who died during the same time period from less recognized causes of limited life expectancy.

We hypothesized that individuals with conditions most clinicians would recognize as incurable, progressive, and life_-or "recognizable, life-limiting conditions"- - would have statins discontinued sooner than those without. We examined the influence of certain diagnoses rather than patients' prognoses because physicians are more accurate at diagnosing than they are at prognosticating, and because they consider the benefits of treatment more than they consider the patient's prognosis in decisions about withholding or withdrawing care. ${ }^{22-27} \mathrm{We}$ expected that statin discontinuation would be less common for patients with known heart disease since, for them, the evidence for continued statin therapy might be stronger. We considered the possibility that comorbidities, severity of illness, as well as number of pills dispensed could affect this relationship. As a secondary objective, we examined the expenditures of the Veterans Health Administration (VHA) on statins for these patients as well.

\section{METHODS}

\section{Design}

We used a matched case-control design, with cases and controls matched on number of comorbidities, age, and socioeconomic status. Our study was nested within a cohort of patients seen for any service (inpatient, outpatient, laboratory, and/or pharmacy) who died between July 1, 2004 and June 30, 2005 and had statins in hand 6 months prior to death. We chose 6 months as the cutoff point to match the typical life expectancy cut off used to define an illness as "terminal." We chose to examine decedents only (as both cases and controls) to minimize confounding by factors that we could otherwise not adjust for (e.g., social support, function, symptom burden, caregiver status, intensity of care).

\section{Setting}

Our population received care at VHA medical centers within Veterans Integrated Service Network (VISN) 11. VISN 11 is one of 22 integrated networks of care for the VHA. VISN 11 represents 8 hospitals, 22 outpatient clinics, and 7 counseling centers in Michigan, Illinois, and Indiana. Together, VISN 11 facilities served approximately 219,978 patients during our period of study. We chose VISN 11 for convenience of data extraction.

\section{Data sources}

We used clinical and pharmaceutical data from the VHA. The VHA, which operates on a fixed annual budget that covers pharmaceuticals in addition to staff salaries, clinical services, facilities management, and supplies, closely tracks pharmaceutical expenditures. To prevent the double-digit annual increases in pharmacy costs seen nationally, ${ }^{28}$ the VHA has implemented several mechanisms to control pharmacy costs, including a national formulary consisting of over 1200 prescription and over-the-counter drugs in 254 classes. In addition, the VHA maintains a database (Decision Support System Pharmacy National Extracts) to track prescription practices and expenditures, on which we relied for this study. The same source of data has been successfully used to estimate drug costs for the VHA which, in turn, have been extrapolated to the private sector. ${ }^{29}$ Clinical data came from national claims data kept at the VHA Austin Automation Center.

\section{Case-control selection}

Figure 1 illustrates the process of case and control selection. Our initial cohort consisted of veterans who died during our period of study and had a statin dispensed prior to death. From this cohort, we selected potential cases as those carrying a recognizable, life-limiting condition prior to death; that is, a condition that most clin- 


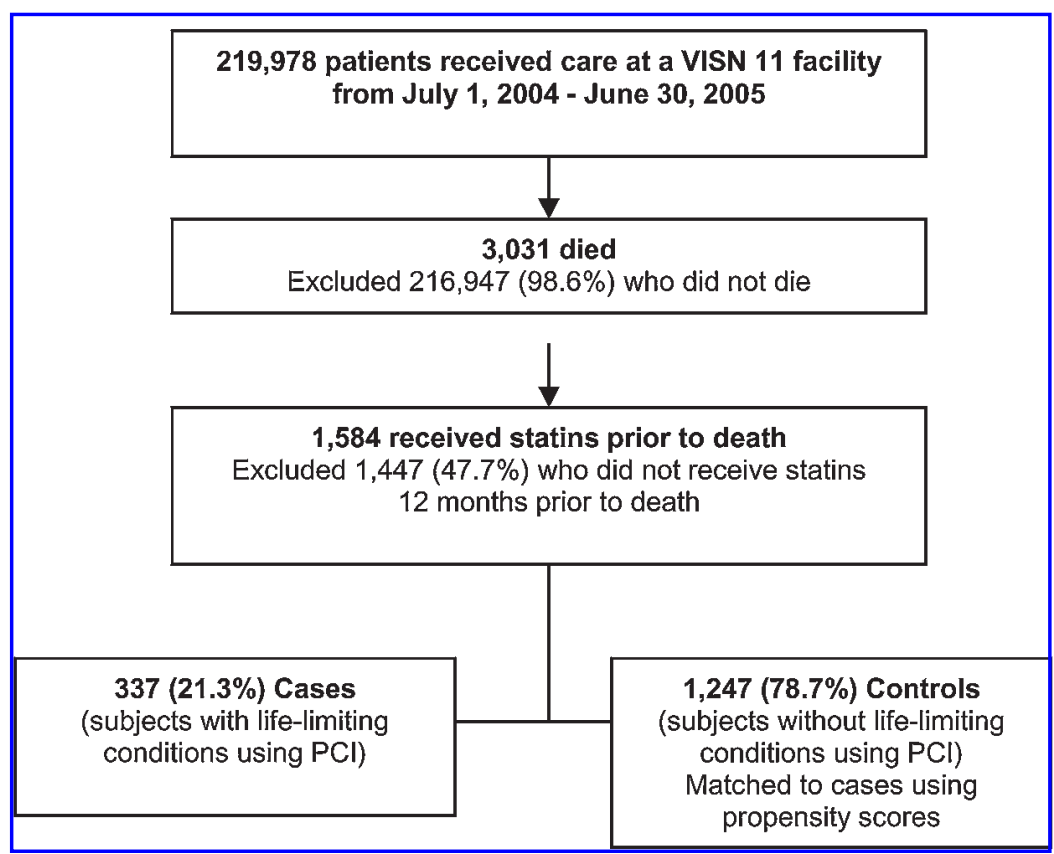

FIG. 1. Flow chart for case selection and matching.

icians would identify as incurable, progressive, and lifeshortening. We identified cases by the presence of a diagnostic claim for a recognizable, life-limiting condition on any single outpatient or inpatient visit to VISN 11 (the former reported by the physician, the latter determined by a coder reviewing the discharge summary). For "recognizable, life-limiting conditions" we used those used to determine the VHA's Palliative Care Index (PCI; Table 1). The PCI was developed in 1998 by

Table 1. Palliative Care Index Diagnoses

\begin{tabular}{ll}
\hline ICD-9-CM & \multicolumn{1}{c}{ Diagnosis } \\
\hline 150 & Esophageal cancer \\
155 & Liver cancer \\
157 & Pancreatic cancer \\
162 & Broncho-tracheal-lung cancer \\
153 & Colon cancer \\
$204-208$ & Leukemia \\
201 & Hodgkin's \\
203.0 & Multiple myeloma \\
198.81 & Metastatic breast cancer \\
198.82 & Metastatic prostate cancer \\
042 & AIDS \\
428 & CHF (2 or more admissions or 1 ICU \\
& stay in last 6 months) \\
$490-496$ & COPD (2 or more admissions or 1 ICU \\
& stay in last 6 months)
\end{tabular}

ICD-9-CM, International Classification of Diseases, Ninth Revision, Clinical Modification; AIDS, acquired immune deficiency syndrome; $\mathrm{CHF}$, congestive heart failure; ICU, intensive care unit; COPD, chronic obstructive pulmonary disease. a group of VHA clinical experts as a performance measure. ${ }^{30}$ Within our cohort, we identified 337 cases who carried a PCI diagnosis prior to death.

We identified controls by matching those remaining in the cohort to cases using propensity scores ${ }^{31}$ for independent variables that could confound the relationship between recognizable, life limiting condition and statin discontinuation: namely, number of comorbidities, age, and prescription copay status. Comorbidities were classified according to Quan's modified Charlson Comorbidity Index. ${ }^{32}$ We used the count of Charlson comorbidities, rather than the weighted Charlson score ${ }^{33}$ as a reflection of burden of illness (or the overall number of conditions a subject carried). Age was the age at death. VHA copay status was included because ability to pay for medications has been shown to be a major driving force behind patient decisions to fill prescriptions and discontinue medications. ${ }^{34-36}$ Copay status at the VHA is determined using the veteran's self-reported net worth, conditions acquired during their time of service (known as "service connection"), and prisoner of war status. There are three categories of copay status: full copay for all medications, full copay for some medications, and no copay on any medications. By matching propensity scores, we identified 1247 patients as controls.

We deliberately chose not to match subjects by ethnicity, gender, and low density lipoprotein (LDL) level. We excluded ethnicity due to the lack of reporting in the VHA Medical Dataset. We excluded 
gender because women in the VHA are few in number $(6 \%$ of outpatients and $4 \%$ of inpatients during the year of the study) $)^{37}$ and women are usually younger than males (mean age $=48.8$ years old for female VHA patients versus 63.6 years old for male VHA patients). We excluded LDL because results were not available for more than two thirds of subjects (less than one fourth of the cases had their LDL levels checked within 6 months before death) and because we felt that LDL status was unlikely to confound the relationship between life-limiting condition and statin discontinuation since LDL level, while a condition for initiation of statin therapy, is not a criterion for discontinuation.

With this sample size, we had $90 \%$ power to detect a difference in proportions as small as $10 \%$ between the groups $(\alpha=0.05)$.

\section{Outcome of interest}

Our outcome of interest was the number of days from the day prescribed statins ran out and the day the patient died. This outcome was determined using the date when a statin was dispensed, how many pills were dispensed at the time, and the date of death. We counted all pills dispensed to patients, even if the prescription had been discontinued at some point after the last refill, in order to account for the true expenditures of the VHA and because we did not have the ability to examine the actual number of pills taken by patients. We did not examine the use of nonstatin lipid-lowering medications since they have not been the focus of debate.

\section{Predictors and confounders}

Our main predictor of interest was the presence or absence of a recognizable, life-limiting condition. We chose this predictor in keeping with the mechanism of action that would support our hypothesis; namely, that if a physician discontinues a statin for a patient before death, it is probably because the physician recognizes the patient has an incurable, progressive, and life-limiting illness for whom statins are no longer of value. We chose to measure the presence of a recognizable, life limiting condition using Palliative Care Index (PCI) diagnoses because the diagnoses used to calculate the PCI were chosen to identify patients who most clinicians would agree need palliative care, not only because of their limited life expectancy, but also because of their great burden of suffering and poor quality of life. ${ }^{30}$ Patients carrying a PCI diagnoses are those for-whom a discussion of prognosis and goals of care is especially indicated; indeed, the VHA expects $95 \%$ of such patients to have documentation of an advance care plan (unless they are receiving hospice or homebased care). A PCI diagnosis, therefore, is one which should flag a physician to discuss, among many things, the goals of continued medical treatment.

Our confounders of interest were weighted Charlson score (as opposed to the Charlson count used for matching) and number of pills supplied (either 30 or 90 for most subjects due to automation at the VHA). We used the weighted Charlson score ${ }^{32,33}$ to reflect the overall severity of illness as modified by age. Some diagnoses were considered in both the calculation of the weighted Charlson score and the determination of the PCI. Despite this, we did not identify any colinearity between the weighted Charlson score and the PCI.

\section{Analyses}

We generated frequency statistics to support the matching process as well as describe the study sample. According to the nature of the variables, we compared cases and controls using chi-square, Pearson Product Moment Correlation, Point-Biserial correlation, or Spearman's $\rho$.

We used survival analysis to test the relationship between days without statins and the presence or absence of a life limiting condition, while controlling for pills supplied and weighted Charlson score.

All statistics were run using SAS ${ }^{\circledR}$ 9.1.3 software (SAS Institute Inc., Cary, NC).

\section{Human subjects considerations}

The study was granted exemption status by the Institutional Review Board at the VA Ann Arbor Healthcare System given the use of deidentified, decedent data.

\section{RESULTS}

\section{Study population}

Of the 3031 individuals who died in VISN 11 between July 1, 2004 and June 30, 2005, 1584 (52.3\%) were receiving statins in the 6 months prior to death. Of those, 337 were diagnosed with a life limiting condition and served as our cases. Using the method described above, we identified 1247 controls.

Cases and controls were mostly elderly, married, white, and male (Table 2). They did not differ significantly from each other in copay status, gender, race, or age at death. They did differ, however, in marital status (Cramer's V $=0.1086, p=0.0047$ ) and several 
Table 2. Characteristics of Cases and Controls $(n=1584)$

\begin{tabular}{|c|c|c|c|}
\hline & & $\begin{array}{l}\text { Cases } \\
\mathrm{n}(\%)\end{array}$ & $\begin{array}{c}\text { Controls } \\
\mathrm{n}(\%)\end{array}$ \\
\hline Number of subjects & & $337(21.3)$ & $1247(78.7)$ \\
\hline \multirow[t]{4}{*}{ Pharmacy copay status } & Some copay & $238(70.6)$ & $780(62.6)$ \\
\hline & No copay & $59(17.5)$ & $193(15.5)$ \\
\hline & All copay & $40(11.9)$ & $270(21.6)$ \\
\hline & Unknown & $0(0)$ & $4(0.3)$ \\
\hline Gender & Male & $337(100)$ & 1239 (99.4) \\
\hline \multirow[t]{4}{*}{ Race } & White & $158(46.9)$ & $535(42.7)$ \\
\hline & Black & $39(11.6)$ & $37(3.0)$ \\
\hline & Missing/unknown & 139 (41.2) & $668(53.4)$ \\
\hline & Other & $1(0.3)$ & $7(0.6)$ \\
\hline \multirow{6}{*}{ Marital status } & Married & $172(51.0)$ & $771(61.8)$ \\
\hline & Divorced & $88(26.1)$ & $214(17.2)$ \\
\hline & Widowed & $56(16.6)$ & $174(14.0)$ \\
\hline & Never married & $20(5.9)$ & $85(6.8)$ \\
\hline & Separated & $1(0.3)$ & $2(0.2)$ \\
\hline & Unknown & $0(0)$ & $1(0.1)$ \\
\hline \multirow[t]{17}{*}{ Charlson comorbidities } & Any malignancy & $217(64.4)^{\mathrm{a}}$ & $164(13.2)$ \\
\hline & Chronic obstructive pulmonary disease & $196(58.2)$ & $374(30.0)^{\mathrm{a}}$ \\
\hline & Congestive heart failure & $168(49.9)$ & $360(28.9)^{\mathrm{a}}$ \\
\hline & Diabetes mellitus & $169(50.1)$ & $562(45.1)$ \\
\hline & Peripheral vascular disease & $91(27.0)$ & $227(18.2)^{\mathrm{a}}$ \\
\hline & Diabetes with chronic complications & $81(24.0)$ & $176(14.1)^{\mathrm{a}}$ \\
\hline & Metastatic solid tumor & $76(22.6)^{\mathrm{a}}$ & $27(2.2)$ \\
\hline & Cerebrovascular disease & $71(21.1)$ & $200(16.0)^{\mathrm{b}}$ \\
\hline & Renal disease & $67(19.9)$ & $177(14.2)^{\mathrm{a}}$ \\
\hline & Myocardial infarction & $73(21.7)$ & $130(10.4)^{\mathrm{a}}$ \\
\hline & Mild liver disease & $28(8.3)^{\mathrm{a}}$ & $21(1.7)$ \\
\hline & Peptic ulcer disease & $16(4.7)$ & $37(3.0)$ \\
\hline & Dementia & $12(3.6)$ & $57(4.6)$ \\
\hline & Rheumatic disease & $6(1.8)$ & $26(2.1)$ \\
\hline & Hemiplegia or paraplegia & $5(1.5)$ & $13(1.0)$ \\
\hline & Moderate or severe liver disease & $6(1.8)^{\mathrm{a}}$ & $3(0.2)$ \\
\hline & AIDS/HIV & $1(0.3)$ & $0(0)$ \\
\hline \multirow[t]{5}{*}{ Palliative care index diagnosis } & $\mathrm{CHF}$ & $104(30.9)$ & N/A \\
\hline & COPD & $114(33.8)$ & N/A \\
\hline & Cancer & $211(57.9)$ & N/A \\
\hline & AIDS/HIV & $1(0.3)$ & N/A \\
\hline & & Mean (SD) & Mean (SD) \\
\hline Age (at death) & & $72.5(9.1)$ & $74.6(9.9)$ \\
\hline LDL level & & $91.8(40.4)$ & $95.0(32.4)$ \\
\hline Number of Charlson comorbidities & & $3.8(1.8)$ & $2.0(1.6)$ \\
\hline Weighted Charlson score & & $5.6(3.0)$ & $2.3(2.0)$ \\
\hline
\end{tabular}

Significant statistical difference by study group at: ${ }^{\mathrm{a}} p<0.01$; ${ }^{\mathrm{b}} p<0.05$.

AIDS/HIV, acquired immune deficiency syndrome/human immunodeficiency virus; CHF, congestive heart failure; COPD, chronic obstructive pulmonary disease; LDL, low-density lipoprotein.

important clinical variables determined by their case/control classification.

Cases carried a greater severity of illness than controls did. On average, cases had a weighted Charlson score of 5.6 (standard deviation $\mathrm{SD}=3.0$ ) whereas controls had a weighted Charlson score of 2.3 ( $\mathrm{SD}=$ 2.0). Cases were significantly more likely than controls to suffer from any malignancy $(p<0.0001)$, metastatic cancer $(p<0.0001)$, and mild $(p=$
$0.0008)$ or moderate to severe $(p<0.0001)$ liver disease; while controls were significantly more likely than cases to suffer from myocardial infarction $(p<$ $0.0001)$, congestive heart failure $(p<0.0001)$, peripheral vascular disease $(p=0.0003)$, cerebrovascular disease $(p=0.0296)$, chronic obstructive pulmonary disease $(p<0.0001)$, renal disease $(p<$ $0.0103)$, and diabetes with complications $(p<$ 0.0001). Among cases, the most common life limiting 
conditions (i.e., PCI diagnoses) were advanced cancer (57.9\%), COPD (33.8\%), and CHF (30.9\%).

To confirm the validity of the PCI as a way of identifying a recognizable life limiting condition, we obtained cause of death data from the National Death Index for cases and controls in aggregate (we did not have access to cause of death by individual). Cases were more likely than controls to die from cancer (odds ratio [OR] 5.49, $\leq 0.0001)$ and less likely than controls to die from heart disease (heart attacks and congestive heart failure could not be disentangled) (OR $0.41, \leq 0.0001$ ), cerebrovascular disease (acute stroke versus chronic cerebrovascular disease could not be disentangled), and "sudden death" (which included accidents, infections, sepsis, suicide, and assault) (OR $0.31, p=0.0009$ ). Cases and controls did not differ significantly in other causes of death (specifically, respiratory disease, diabetes, Alzheimer's disease, liver disease, renal disease, hypertension, Parkinson's disease, and "all other").

\section{Statin use}

All subjects were receiving statins from the VHA during 6 months prior to death. By the time of death, $51 \%$ of cases and $64 \%$ of controls were still receiving statins. However, there was no significant difference in the days without statins between cases and controls. Those subjects taken off statins had statins discontinued a mean of 65 days $(S D=49.6)$ prior to death for cases and 64 days $(\mathrm{SD}=50.4)$ prior to death for controls. Our results did not change after stratifying our analyses by illness subgroup (i.e., cancer, CHF, and COPD).

Most statins were dispensed in 90-day increments, regardless of case control status and the number of pills dispensed did not change over time.

\section{Associations}

Days off statins did not associate with having a recognizable, life limiting condition when controlling for weighted Charlson score using Cox proportional hazards modeling (Table 3). It did, however, associate marginally with the number of days of pills supplied (hazard ratio $[\mathrm{HR}]=1.005, p=0.0370$ ), such that for every additional 1 day of pills supplied there was a $0.5 \%$ increased risk of not being taken off a statin.

\section{Cost of statin therapy}

VISN 11 spent $\$ 19,655.83$ for statins dispensed to 335 patients within 6 months of their death from a known life-limiting condition ( 2 cases were missing from the pharmaceutical database).

\section{DISCUSSION}

A large proportion of patients $(52.3 \%)$ receive statins during their last year of life at the VHA. The diagnosis of a recognizable, life limiting illness does not change the timing of or likelihood that a statin will be discontinued prior to death, even for patients without cardiovascular disease. These findings suggest that physicians may not recognize certain conditions as progressive and life limiting, or reassess the benefits and burdens of continued statin therapy when they do. Alternatively, it could mean that physicians find discontinuation of preventive therapies like statins difficult to discuss or that patients are not receptive to the notion that preventive therapies are no longer warranted.

While we saw no difference in statin prescribing patterns by presence of recognizable, life limiting condition, we did witness some statin discontinuation for all patients over time. We feel this decline likely reflects the nature of medications which have side effects, as well as issues with noncompliance, intolerance, and bureaucratic errors. Unfortunately, our data did not include reasons for discontinuation to allow us to test this hypothesis.

Some might argue that our findings can be explained by excess similarity, or colinearity, between our case and control groups. Indeed, our subject selection and case matching protocols were designed to make the two groups as comparable as possible with one exception - the presence of a recognizable, life-limiting condition for cases as defined by the VHA's PCI. That single difference allowed us to test the hypothesis that

Table 3. Maximum Likelihood Estimates for Cox's Proportional Hazards Model

\begin{tabular}{|c|c|c|c|c|c|}
\hline Characteristic & Estimate & $\begin{array}{l}\text { Standard } \\
\text { error }\end{array}$ & $\chi^{2}$ & $\begin{array}{c}\text { Hazard } \\
\text { ratio }\end{array}$ & $\mathrm{p}$ \\
\hline Pills supplied & 0.0049 & 0.0023 & 4.3485 & 1.005 & 0.0370 \\
\hline Weighted Charlson score & 0.0112 & 0.0249 & 0.2037 & 1.011 & 0.6517 \\
\hline Case/control status & -0.0041 & 0.1063 & 0.0015 & 0.996 & 0.9693 \\
\hline
\end{tabular}


individuals who die of conditions recognized to limit life expectancy and burden have statins discontinued sooner than similar individuals who die of causes that are not as predictably fatal or recognized. Some might not agree with our use of PCI diagnoses as "flags" for a recognizable, life limiting condition-however, because it is commonly used to measure palliative care workload within the VHA, we felt it had "face validity" and was appropriate. Still, the PCI has never been empirically validated as a prognosticator of death and some may consider this a major limitation of this work. We wish to emphasize, however, that our predictor of interest was not life expectancy per se, but the "presence of a recognizable, life-limiting condition." Out of many measures we considered, we chose the PCI for our predictor of interest because the PCI most represented those conditions that commonly trigger a discussion of goals of care and the purpose of continued medical treatment.

Others may question the generalizability of our findings. This is a common concern when studies are conducted using VHA data. Admittedly, our subjects are not typical of the general population and our system is not representative of most medical care. However, for us, the feasibility of this study was a strong concern and the convenience of VHA data cannot be overstated. We do acknowledge that in a different population of patients, especially in one that pays out of pocket for medications, our findings may not stand.

Limitations aside, we believe these results highlight an opportunity to reduce the burden of medical therapy upon severely ill patients who often take many medications, have difficulty swallowing, are at greater risk for side effects, and must provide co-pays. Discontinuing statins for such patients not only reduces their burden, but also makes their therapy consistent with the goals of care, especially when cure is no longer a possibility. Doing otherwise could send them mixed messages, making it even more difficult to overcome denial, accept fate, and participate in advance care planning.

In addition to benefiting patients, discontinuing statins may benefit the health care system as a whole by stemming pharmaceutical costs. During our study period, VISN 11 spent $\$ 9.78$ per month per patient, or $\$ 19,655$ total, on statin therapy for 335 patients during their last 6 months of life. While this is a substantial amount for the VHA, it is a fraction of what would have been spent in the private sector where a month's supply of statin costs between $\$ 63.59$ and $\$ 110.99 .{ }^{21}$ Using these numbers, we estimate that in the private sector, $\$ 127,816$ to $\$ 223,090$ dollars would have been spent on the same 335 decedents.
Discontinuing statins in such patients, therefore, could save a lot of money. This cost savings is especially relevant to hospice, which operates on a fixed per diem and must provide all medicationssome hospices do provide nonpalliative medications such as statins (in 2004, Silveira ${ }^{38}$ found that $24 \%$ of hospices in Michigan are willing to provide medications not directly related to the terminal diagnosis).

This study is meant to describe the current pattern of statin use at the end of life in the VHA, not recommend the appropriate timing or criteria for statin discontinuation. When and where to discontinue statins are questions we pose to the community of palliative care and hospice providers at large. For the time being, without better data on the benefits and burdens of statin therapy for patients with progressive, life limiting conditions, we must be guided by clinical prudence.

In conclusion, we find that statins are prescribed frequently in the last year of life for patients carrying recognizable, life-limiting conditions and that the patient's diagnosis does not appear to affect prescribing patterns. The small amount of discontinuation we did observe in the last 6 months of life occurs for reasons we have yet to understand. Still, our findings highlight an area for discussion as a specialty and potential intervention in the future.

\section{ACKNOWLEDGMENTS}

This research was supported by core funds from the VA Health Services Research and Development Center of Excellence, Ann Arbor, Michigan. Dr. Silveira's salary was supported by a VA Career Development Award and a Robert Wood Johnson Generalist Scholar Award.

The authors alone are responsible for the views, opinions, and conclusions expressed herein.

\section{REFERENCES}

1. Sever PS, Dahlof B, Poulter NR, Wedel H, Beevers G, Caulfield M, Collins R, Kjeldsen SE, Kristinsson A, McInnes GT, Mehlsen J, Nieminen M, O’Brien E, Ostergren J; ASCOT Investigators: Prevention of coronary and stroke events with atorvastatin in hypertensive patients who have average or lower-than-average cholesterol concentrations, in the Anglo-Scandinavian Cardiac Outcomes Trial-Lipid Lowering Arm (ASCOT-LLA): A multicentre randomised controlled trial.[see comment]. Lancet 2003;361:1149-1158. 
2. Shepherd J, Blauw GJ, Murphy MB, Bollen EL, Buckley BM, Cobbe SM, Ford I, Gaw A, Hyland M, Jukema JW, Kamper AM, Macfarlane PW, Meinders AE, Norrie J, Packard CJ, Perry IJ, Stott DJ, Sweeney BJ, Twomey C, Westendorp RG; PROSPER study group. PROspective Study of Pravastatin in the Elderly at Risk. Pravastatin in elderly individuals at risk of vascular disease (PROSPER): A randomised controlled trial [see comment]. Lancet 2002;360:1623-1630.

3. Heart Protection Study Collaborative G. MRC/BHF Heart Protection Study of cholesterol lowering with simvastatin in 20,536 high-risk individuals: A randomised placebocontrolled trial [see comment; summary for patients in Curr Cardiol Rep 2002;4:486-487]. Lancet 2002;360:7-22.

4. Collins R, Armitage J, Parish S, Sleigh P, Peto R, Heart Protection Study Collaborative G. MRC/BHF Heart Protection Study of cholesterol-lowering with simvastatin in 5963 people with diabetes: A randomised placebo-controlled trial.[see comment]. Lancet 2003;361:2005-2016.

5. Huang ES, Meigs JB, Singer DE. The effect of interventions to prevent cardiovascular disease in patients with type 2 diabetes mellitus [see comment]. Am J Med 2001;111: 633-642.

6. Serruys PW, de Feyter P, Macaya C, et al. Fluvastatin for prevention of cardiac events following successful first percutaneous coronary intervention: a randomized controlled trial.[see comment]. JAMA 2002;287:3215-3222.

7. ALLHAT Officers and Coordinators for the ALLHAT Collaborative Research Group. The Antihypertensive and Lipid-Lowering Treatment to Prevent Heart Attack Trial: Major outcomes in moderately hypercholesterolemic, hypertensive patients randomized to pravastatin vsusual care: The Antihypertensive and Lipid-Lowering Treatment to Prevent Heart Attack Trial (ALLHAT-LLT) [see comment]. JAMA 2002;288:2998-3007.

8. Athyros VG, Papageorgiou AA, Mercouris BR, Athyrou VV, Symeonidis AN, Basayannis EO, Demitriadis DS, Kontopoulos AG: Treatment with atorvastatin to the National Cholesterol Educational Program goal versus 'usual' care in secondary coronary heart disease prevention. The GREek Atorvastatin and Coronary-heart-disease Evaluation (GREACE) study [see comment]. Curr Med Res Opin 2002;18:220-228.

9. Pignone M, Phillips C, Mulrow C: Use of lipid lowering drugs for primary prevention of coronary heart disease: Meta-analysis of randomised trials [see comment]. BMJ 2000;321:983-986.

10. Cucherat M, Lievre M, Gueyffier F: Benefices cliniques des traitements hypocholesterolemiants. Meta-analyse des essais therapeutiques randomises. Presse Medicale 2000; 29:965-976.

11. Katerndahl DA, Lawler WR. Variability in meta-analytic results concerning the value of cholesterol reduction in coronary heart disease: A meta-meta-analysis. Am J Epidemiol 1999;149:429-441.

12. Ebrahim S, Davey Smith G, McCabe C, Payne N, Pickin M, Sheldon TA, Lampe F, Sampson F, Ward S, Wannamethee G: What role for statins? A review and economic model. Health Technol Assess 1999;3:i-iv.
13. LaRosa JC, He J, Vupputuri S: Effect of statins on risk of coronary disease: A meta-analysis of randomized controlled trials [see comment; summary for patients in J Am Geriatr Soc 2002;50:391-393]. JAMA 1999;282:2340-2346.

14. Sawayama Y, Shimizu C, Maeda N, Tatsukawa M, Kinukawa N, Koyanagi S, Kashiwagi S, Hayashi J.Effects of probucol and pravastatin on common carotid atherosclerosis in patients with asymptomatic hypercholesterolemia. Fukuoka Atherosclerosis Trial (FAST). J Am Coll Cardiol 2002;39:610-616.

15. Amarenco P, Labreuche J, Lavallee P, Touboul PJ: Statins in stroke prevention and carotid atherosclerosis: Systematic review and up-to-date meta-analysis. Stroke 2004;35: 2902-2909.

16. Gami A: Secondary prevention of ischaemic cardiac events (new). In: Tovey D (ed): Clinical Evidence. London: BMJ Publishing; 2004. http://www.clinicalevidence.com/ceweb/ conditions/aid/0206/0206_I29.jsp accessed 1/26/2006.

17. Foster C, Murphy M, Nicholas JJ, Pignone M, Bazian Ltd: Primary prevention. In: Tovey D (ed): Clinical Evidence. London: BMJ Publishing; 2002. http://www.clinicalevidence.com/ceweb/conditions/aid/0205/0205_I19.jsp accessed 1/26/2006.

18. Ballantyne CM, Corsini A, Davidson MH, Holdaas H, Jacobson TA, Leitersdorf E, März W, Reckless JP, Stein EA: Risk for myopathy with statin therapy in high-risk patients [see comment]. Arch Intern Med 2003;163:553-564.

19. Corsini A, Bellosta S, Baetta R, Fumagalli R, Paoletti R, Bernini F: New insights into the pharmacodynamic and pharmacokinetic properties of statins [erratum appears in Pharmacol Ther 2000;86:199]. Pharmacol Ther 1999;84:413-428.

20. Shek A, Ferrill MJ: Statin-fibrate combination therapy. Ann Pharmacother 2001;35:908-917.

21. Vollrath AM, Sinclair C, Hallenbeck J: Discontinuing cardiovascular medications at the end of life: lipid-lowering agents. J Palliat Med 2005;8:876-881.

22. Christakis NA, Sachs GA: The role of prognosis in clinical decision making. J Gen Intern Med 1996;11:422-425.

23. Christakis NA, Lamont EB: Extent and determinants of error in doctors' prognoses in terminally ill patients: Prospective cohort study. BMJ 2000;320:469-472.

24. Christakis NA, Iwashyna TJ: Attitude and self-reported practice regarding prognostication in a national sample of internists. Arch Intern Med 1998;158:2389-2395.

25. Christakis NA, Asch DA: Physician characteristics associated with decisions to withdraw life support. Am J Public Health 1995;85:367-372.

26. Lynn J, Teno JM, Harrell FE, Jr: Accurate prognostications of death. Opportunities and challenges for clinicians. West J Med 1995;163:250-257.

27. Lynn J, Arkes HR, Stevens M, Cohn F, Koenig B, Fox E, Dawson NV, Phillips RS, Hamel MB, Tsevat J: Rethinking fundamental assumptions: SUPPORT's implications for future reform. Study to Understand Prognoses and Preferences and Risks of Treatment [see comment]. J Am Geriatr Soc 2000;48(5 Suppl):S214-221.

28. Smith C, Cowan C, Heffler S, Catlin A: National health spending in 2004: recent slowdown led by prescription drug spending. Health Aff (Millwood) 2006;25:186-196. 
29. Render ML, Nowak J, Hammond EK, Roselle G: Methods for estimating and comparing VA outpatient drug benefits with the private sector. Med Care 2003;41(6 Suppl):II61-69.

30. Office of Performance and Quality: 1999 Network Directors' Performance Measures: Definitions and Data Collection Strategies. Washington D.C.: Veterans Health Administration, April 91999.

31. Rosenbaum PR, Rubin DB: The central role of propensity scores in obervational studies for causal effects. Biometrika 1983;70:41-55.

32. Quan H, Sundararajan V, Halfon P, Fong A, Burnand B, Luthi JC, Saunders LD, Beck CA, Feasby TE, Ghali WA: Coding algorithms for defining comorbidities in ICD-9-CM and ICD-10 administrative data. Med Care 2005;43: 1130-1139.

33. Charlson ME, Pompei P, Ales KL, MacKenzie CR: A new method of classifying prognostic comorbidity in longitudinal studies: Development and validation. J Chron Dis 1987;40:373-383.

34. Dor A, Encinosa W: Does cost sharing affect compliance? The case of prescription drugs. NBER Working Paper Series 2004.
35. Heisler M, Langa KM, Eby EL, Fendrick AM, Kabeto MU, Piette JD: The health effects of restricting prescription medication use because of cost [see comment]. Med Care 2004;42:626-634.

36. Goldman DP, Joyce GF, Karaca-Mandic P: Varing pharmacy benefits with clinical status: the case of cholesterollowering therapy. Am J Manag Care 2006;12:21-28.

37. VIREC (VA Information Resource Center): Select Variable Frequencies from the VHA Medical SAS Datasets. Hines, IL: VHA; 2004.

38. Silveira MJ, Raju S: Restrictive hospice operating practices in Michigan. (in preparation).

Address reprint requests to: Maria J. Silveira, M.D. 300 North Ingalls Building Room 7C27, Box 0429 Ann Arbor, MI 48105

E-mail: mariajs@umich.edu 
This article has been cited by:

1. HM Holmes. 2009. Rational Prescribing for Patients With a Reduced Life Expectancy. Clinical Pharmacology \&\#38; Therapeutics 85:1, 103-107. [CrossRef] 